\title{
Evaluation of the Intermental Foramina Distance among Malaysian Population by using Orthopantomogram Radiograph
}

\author{
${ }^{1}$ Mohammed Jasim Al-Juboori, ${ }^{2}$ Rajiv Saini, ${ }^{3}$ Hussien Ali Al-Wakeel, ${ }^{4}$ Lor Yen Fang , ${ }^{5}$ Navenithamaria Eirutharajan \\ ${ }^{6}$ Santhanalaxmi A Balachandran
}

\begin{abstract}
Objectives: Previous studies showed there were variations in the interforamina distance of mental foramen between races. The aim of our study is to determine the interforamina distance of mental foramen among Malaysian populations.
\end{abstract}

Materials and methods: A total of 503 orthopantomogram (OPG) radiographs were observed. Interexaminer calibration was estimated using the Kappa-Cohen formula. A sheet of transparent paper was superimposed on the panoramic film and the mental foramen was traced on it by using a fine marker pen. A vertical line marking the midline was drawn passing between the maxillary central incisors, the mandibular central incisors, or the nasal septum by using a ruler. The distance of the mental foramen from the midline was then recorded from both the left and the right side. The data were analyzed using chi-square test.

Results: According to our inclusion and exclusion criteria, 110 OPGs have been excluded and 393 OPGs were selected. In the Malay population, the most common interforamina distance for a male is between 55 and $60^{+} \mathrm{mm}(\mathrm{n}=73,54.8 \%)$. Also, the most common interforamina distance for a female is 55 to $60^{+} \mathrm{mm}(\mathrm{n}=84,50 \%)$. In the Chinese population, the most common interformina distance for a male is between 55 and $60^{+} \mathrm{mm}(\mathrm{n}=60,66.8 \%)$. Similarly, the most common interforamina distance for a female is between 55 and $60^{+} \mathrm{mm}(n=73,53.8 \%)$. Among the Indian population, the most common interforamina distance for a male falls between 55 and $60^{+} \mathrm{mm}(n=53,43.4 \%)$ and for a female as well $(n=50,54 \%)$. According to the chi-square test, the results show that the study is statistically insignificant since the $p$-value is $>0.05$ for both the male and female population.

Conclusion: There is no relationship between the interforamina distance and the ethnicity. The most common interforamina distance for all the races falls between 55 and $60^{+} \mathrm{mm}$.

\footnotetext{
${ }^{1}$ Lecturer, ${ }^{2}$ Associate Professor, ${ }^{3}$ Dental Officer, ${ }^{4-6}$ Under Graduate Student

${ }^{1}$ Department of Periodontology, Al Rafidain University College Mustansiriya, Baghdad, Iraq; Dental Faculty, MAHSA College Pusat Bandar Damansara, Kuala Lumpur, Malaysia

${ }^{2}$ Department of Periodontology, Pravara Institute of Medical Sciences, Loni, Maharashtra, India

${ }^{3}$ Department of Surgery, International Medical University Wilayah Persekutuan, Kuala Lumpur, Malaysia

${ }^{4-6}$ Dental Faculty, MAHSA University College, Pusat Bandar Damansara, Kuala Lumpur, Malaysia
}

Corresponding Author: Mohammed Jasim Al-Juboori, Lecturer Department of Periodontology, Al Rafidain University College Mustansiriya, Baghdad, Iraq, Phone: (+964)7714559551, e-mail: doctor_mohamed_2006@yahoo.com
Keywords: Interforamina distance, Malaysian, Mental foramen, Orthopantomogram, Races.

How to cite this article: Al-Juboori MJ, Saini R, Al-Wakeel HA, Fang LY, Eirutharajan N, Balachandran SA. Evaluation of the Intermental Foramina Distance among Malaysian Population by using Orthopantomogram Radiograph. Int J Experiment Dent Sci 2016;5(2):118-122.

Source of support: Nil

Conflict of interest: None

\section{INTRODUCTION}

It has been found that the location of the mental foramen varies in different ethnicity. ${ }^{1}$ Mental foramen position is commonly seen below the second premolar. ${ }^{2}$ However, individual variation exists whereby it can be placed anywhere in between the first premolar to the mesial root of the first molar. ${ }^{3}$

The position of the mental foramen can be seen in two different planes, which are the horizontal and the vertical planes. ${ }^{4}$ Fishel et $\mathrm{al}^{4}$ and Greenstein et $\mathrm{al}^{5}$ have proposed the most popular method for the identification of mental foramen. The horizontal position of mental foramen was recorded as either in line with the longitudinal axis of the tooth or lying in between two teeth. ${ }^{4}$ Fishel et $\mathrm{ll}^{4}$ described the vertical position of the mental foramen to be either situated coronal to the apex, at the apex, or apical to the apex.

Some studies measured the location of the mental foramen from various landmarks of the mandible. For instance, the most commonly used landmarks are symphysis menti, ${ }^{6}$ posterior border of the ramus of the mandible (in horizontal plane), and the lower border of the body of the mandible (in vertical plane). ${ }^{3}$

To estimate the distance of the interforamina, various studies have been done by using the midline of the mandible as an anatomical landmark. According to Shankland, ${ }^{3}$ the mandibular foramen is located $28 \mathrm{~mm}$ from the midline of the mandible and $14-15 \mathrm{~mm}$ from the inferior border of the mandible. ${ }^{3}$ On the contrary, Neiva et $\mathrm{al}^{7}$ proposed that the distance of this foramen from midline was $27.61 \pm 2.29 \mathrm{~mm}$. Neiva et $\mathrm{al}^{7}$ also studied about the interforamina distance and found that the distance between the left and right foramen was $55.23 \pm 5.34 \mathrm{~mm}$. Another study that was done by Apinhasmit et $\mathrm{al}^{8}$ found that the mental foramen was a mean of $28.52 \pm 2.15 \mathrm{~mm}$ from the 
midline of the mandible. For the purpose of implant placement in the interforamina area of complete edentulous patient, interforamina distance is crucial in determining the location and the number of implant placement. Our study chose the Malaysian population that is compose of the three main ethnic groups, Malay, Chines, and Indian, to detect the interforamina distance. To our knowledge, this is the first study conducted in such ethnic population.

\section{MATERIALS AND METHODS}

A total of 503 panoramic radiographs orthopantomogram (OPG) of Malay, Chinese, and Indian adult patients of both sexes having visible mental foramina bilaterally were collected. All panoramic radiographs were taken using Siemen Orthophos (Sirona) with magnification of 1.2. The radiographs were chosen according to the following inclusion and exclusion criteria.

\section{Inclusion Criteria}

- Age 18 and above.

- Malaysia ethnicity: Malay, Chinese, and Indian.

- High quality with respect to geometric accuracy and contrast of the image.

- Panoramic radiographs having bilaterally visible mental foramina.

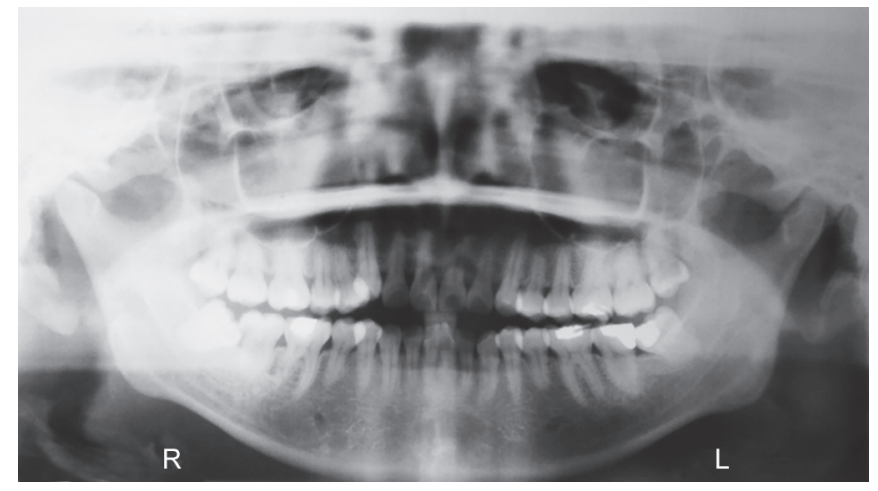

Fig. 1: Panoramic radiograph

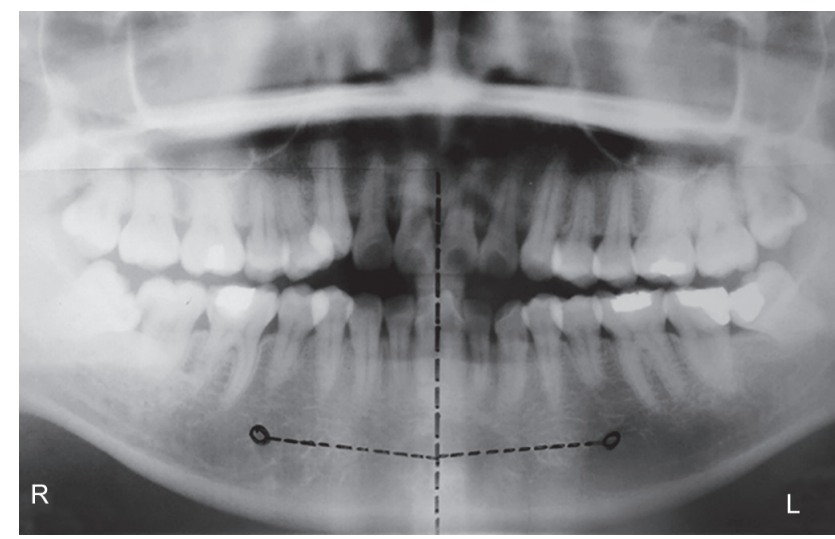

Fig. 3: A fine marker pen is used to highlight the mental foramen on both the right and left side of the mandible, followed by a horizontal line drawn from the most medial aspect of the mental foramen to the midline

\section{Exclusion Criteria}

- Unreadable and poor quality of OPG.

- Radiopaque or radiolucent lesion in the lower arch.

- Evidence of lower jaw fracture around the mental foramen region.

- Presence of supernumerary or unerupted teeth because the impacted or unerupted teeth might obscure the appearance of the mental foramen.

- Any radiographic exposure or processing artifacts. Panoramic radiographs were viewed in a dark room on an X-ray viewer. The mental foramen was identified as a radiolucency by a magnifying glass that can be traced by following the inferior dental canal (Fig. 1). A sheet of transparent paper was superimposed on the panoramic film and the mental foramen was traced on the transparent paper by using a fine marker pen. A vertical line marking the midline was drawn passing between the maxillary central incisors (as first preference), the mandibular central incisors, or the nasal septum (if the maxillary and mandibular central incisors were missing) by using a ruler (Fig. 2). This was followed by, a horizontal line that was drawn from the most medial aspect of the mental foramen to the midline (Fig. 3). The distance of the horizontal line was then measured on both the right and the left side (Fig. 4). The addition of both these values is the magnified value of

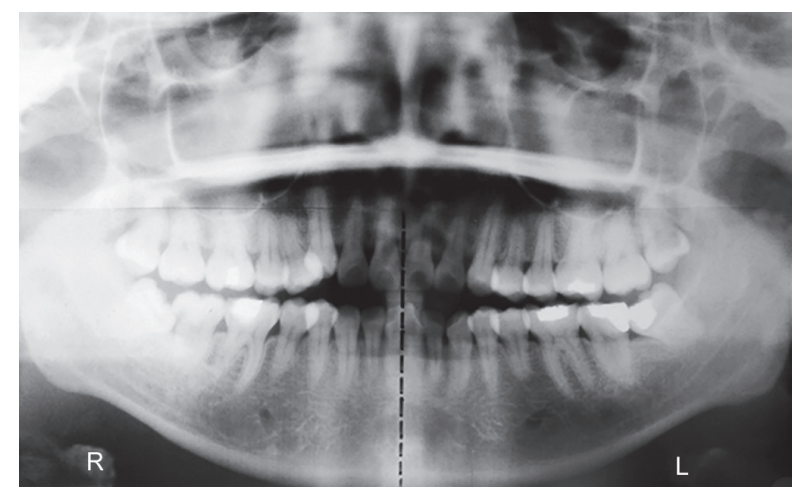

Fig. 2: A vertical line marking the midline was drawn passing between the maxillary central

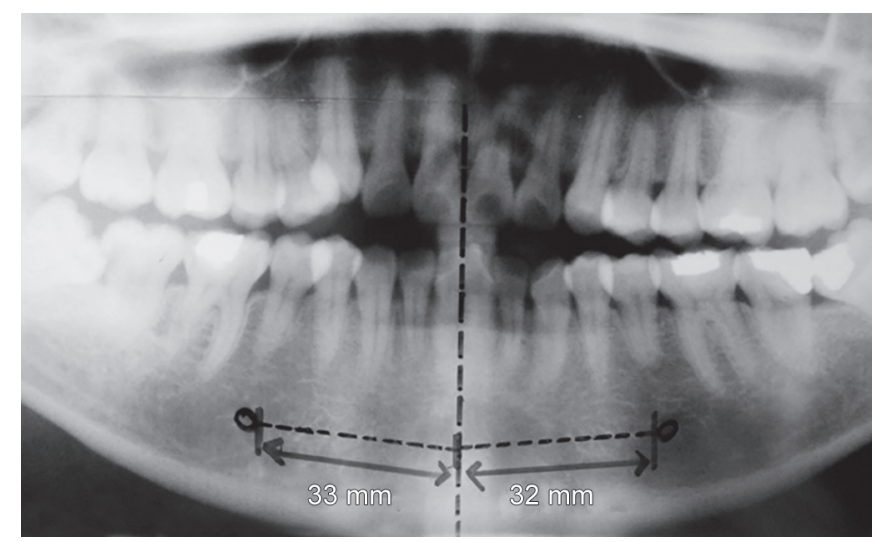

Fig. 4: Orthopantomogram with the measured distance of the mental foramen to the midline on each of the side 
the intermental foramina distance. The length is obtained by dividing the value by 1.2 . The calculated value was grouped into three types as the following according to the ethnicity and gender:

Type I: $40-47 \mathrm{~mm}$

Type II: 48-54 mm

Type III: $54-60^{+} \mathrm{mm}$

Thirty randomly selected panoramic radiographs were studied by three observers to perform the interexaminer calibration, and the Cohen's Kappa formula was used.

$$
\kappa=\frac{\operatorname{Pr}(a)-\operatorname{Pr}(e)}{1-\operatorname{Pr}(e)}
$$

where $\operatorname{Pr}(a)$ is the relative observed agreement among raters.

$\operatorname{Pr}(e)$ is the hypothetical probability of chance agreement.

The interexaminer kappa statistic shows 0.911 (0.81-1 as the almost perfect agreement).

All the data collected were analyzed using chisquare test to show the relation between ethnicity and interforamina distance.

\section{RESULTS}

As many as 393 OPGs were selected out of 503 OPGs based on the exclusion criteria. Of these, 187 were males and 207 were females (Fig. 5). The youngest patient was 18 years old and the oldest was 81 years old. Sex analysis showed a higher female percentage (52.7\%).

Among the Malay population, the average distance of the mental foramen to the midline is $(R=27.47 \pm 5.10 \mathrm{~mm}$, $\mathrm{L}=26.69 \pm 4.97 \mathrm{~mm})$. The average intermental foramina distance however is $54.16 \pm 9.22 \mathrm{~mm}$ (Fig. 6).

On the contrary, the average distance of the mental foramen to the midline among the Chinese population

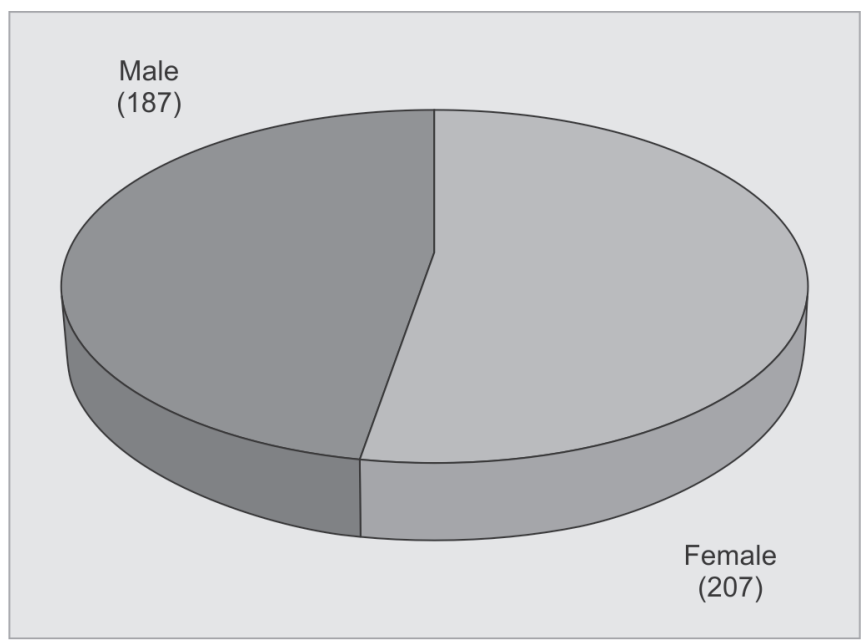

Fig. 5: Distribution of male and female patients is $(\mathrm{R}=28.41 \pm 4.53 \mathrm{~mm}, \mathrm{~L}=27.19 \pm 4.21 \mathrm{~mm})$. The average intermental foramina distance is $55.61 \pm 7.47 \mathrm{~mm}$.

For the Indian population, their average distance from the midline is $(\mathrm{R}=26.9 \pm 5.10 \mathrm{~mm}, \mathrm{~L}=26.59 \pm 5.38 \mathrm{~mm})$. The average intermental foramina distance is $53.5 \pm 9.45 \mathrm{~mm}$.

The average of the intermental foramina distance for the total Malaysian population is $55.47 \pm 8.76 \mathrm{~mm}$ $(\mathrm{R}=27.34 \pm 4.94 \mathrm{~mm}, \mathrm{~L}=26.83 \pm 4.84 \mathrm{~mm})$.

The data collected were divided based on the ethnicity for each sex. The number of Malays that falls into type I category are $(\mathrm{n}=73, \mathrm{M}=17.81 \%)(\mathrm{n}=84, \mathrm{~F}=19.05 \%)$, Chinese are $(n=60, M=10.00 \%)(n=73, F=12.33 \%)$, and Indians are $(n=53, M=20.75 \%)(n=50, F=16.00 \%)$ (Fig. 6).

Next, in type II category, the number of Malays are $(\mathrm{n}=73, \mathrm{M}=27.40 \%)(\mathrm{n}=84, \mathrm{~F}=30.95 \%)$, Chinese are $(\mathrm{n}=60$, $\mathrm{M}=10.00 \%)(\mathrm{n}=73, \mathrm{~F}=32.88 \%)$, and Indians are $(\mathrm{n}=53$, $\mathrm{M}=35.85 \%)(\mathrm{n}=50, \mathrm{~F}=30.00 \%)$ (Fig. 6).

Lastly, the number of Malays that were grouped into type III category are $(\mathrm{n}=73, \mathrm{M}=54.79 \%)(\mathrm{n}=84, \mathrm{~F}=50.00 \%)$, Chinese are $(n=60, M=66.67 \%)(n=73, F=54.79 \%)$, and Indians are $(n=53, M=43.40 \%)(n=50, F=54.00 \%)$ (Fig. 6). The study also calculated the interforamina distance for female and male of Malay, Indian, and Chinese (Figs 7 and 8).

According to the result mentioned, we can say that the most common interforamina distance for each races falls into type III category, which is between 55 and $60^{+} \mathrm{mm}$.

Null Hypothesis $\left(\mathrm{H}_{0}\right)$ : There is no relationship between ethnicity and interforamina distance.

The confidence level of this study is $\alpha<0.05$. The chisquare value obtained both male and female population is 6.596 and 1.387, respectively. The degree of freedom (df) is 4 for both gender. The $\mathrm{p}$-value $(\mathrm{P})$ for male is 0.1591 $(p>0.05)$ and for female is $0.8465(p>0.05)$. Since both the $\mathrm{p}$-values are more than 0.05 , we can say that the test is not statistically significant. Thus, we can accept the null

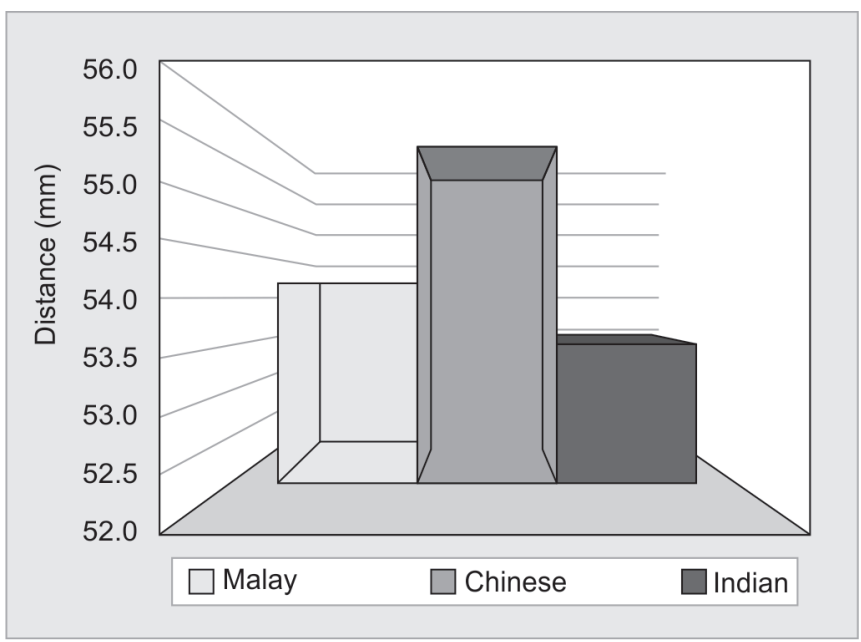

Fig. 6: Average intermental foramina distance among the Malaysian population 


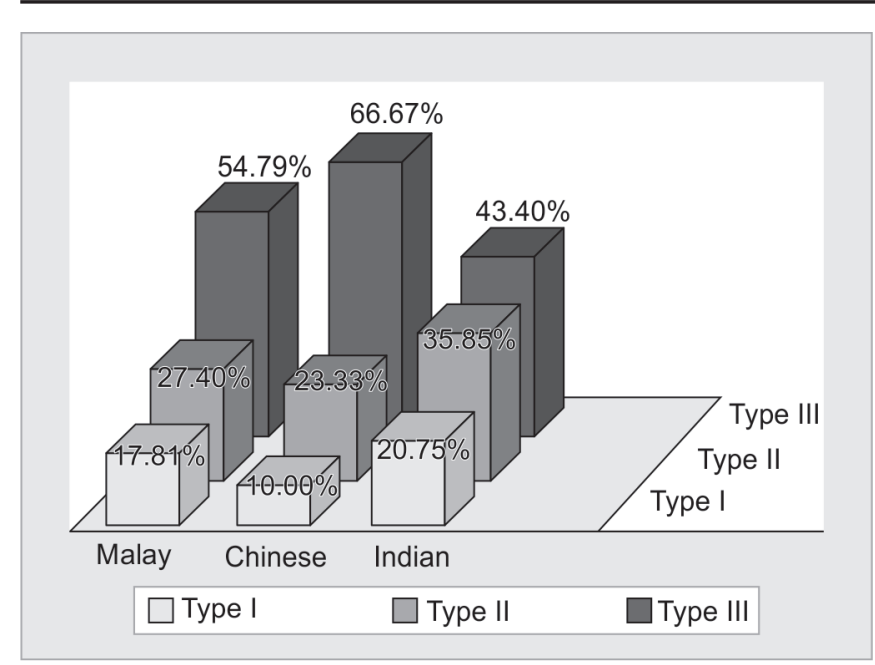

Fig. 7: Percentage of occurrence of each ethnicity in the male population

hypothesis $\left(\mathrm{H}_{0}\right)$ and reject the alternative hypothesis $\left(\mathrm{H}_{\mathrm{a}}\right)$. Therefore, there is no relationship between ethnicity and interforamina distance.

\section{DISCUSSION}

The determination of the intermental foramina distance has been a topic of great interest, especially in implantology, stressing the importance of anatomical landmarks in the maxillofacial region. ${ }^{5}$ The frequent failures reported during administration of local anesthesia and surgical procedures involving the mental foramen highly suggest the presence of variation in different populations. ${ }^{5}$

Based on the study conducted, the average intermental foramina distance in Malaysian population is $54.47 \pm$ $8.76 \mathrm{~mm}$. In cadaveric specimens, Neiva et $\mathrm{al}^{7}$ found that the mean distance between the right and the left mental foramen among Caucasian population is 55.23 \pm $5.34 \mathrm{~mm} \cdot{ }^{2,3} \mathrm{Kim}$ et al, ${ }^{9}$ a Korean researcher and coworkers, have examined 28 hemifacial cadavers and concluded that the distance between the bilateral mental foramina is $50.32 \pm 1.93 \mathrm{~mm}$, comparing with the present Malaysian Chinese population, which is $55.61 \pm 7.47 \mathrm{~mm}$.

In Malaysian Chinese population, the average distance of the right mental foramen to the midline is $28.42 \pm$ $4.53 \mathrm{~mm}$, while on the left side it is $27.19 \pm 4.12 \mathrm{~mm}$. An anatomical study by Wang et $\mathrm{al}^{10}$ involving 100 mandibles of adult Chinese cadaver showed distance of $28.06 \mathrm{~mm}$ from the symphysis.

Among Malaysian Indian population, the average distance of the right mental foramen to the midline is $26.9 \pm 5.10 \mathrm{~mm}$, whereas on the left side it is $26.5 \pm$ $5.38 \mathrm{~mm}$. In comparison with the study directed by Udhaya et $\mathrm{al}^{11}$ on the South Indian population, the values were $25.7 \pm 1.78 \mathrm{~mm}$ and $25.29 \pm 2.29 \mathrm{~mm}$ on right and left sides respectively. Similar study was carried out by

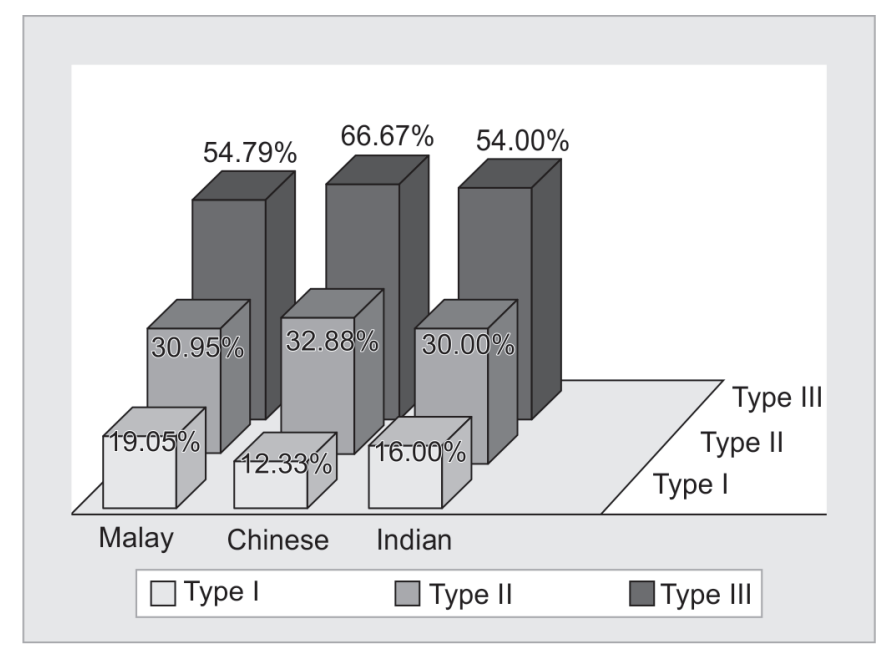

Fig. 8: Percentage of occurrence of each ethnicity in the female population

Singh and Srivastav, ${ }^{2}$ which shows an average distance of $29.3 \mathrm{~mm}$ for the right side and $30.6 \mathrm{~mm}$ for the left side of the mental foramen to the symphysis. On the contrary, Gupta and Soni ${ }^{12}$ have found that the mean distance of both the mental foramens to the midline to be $29.12 \mathrm{~mm}$ among the north Indian Population. In addition to this, according to Prabodra et $\mathrm{al}_{1}^{13}$ the distance of the mental foramen from the symphysis menti among the Sri Lankans is found to be $26.52 \mathrm{~mm}$. Comparing all these studies with the present study, the measurements show small but significant differences in the mental foramina distance to the midline.

The present study provides new data on the distance between the two mental foramina among the Malay population. In the analysis of 164 OPGs, the average intermental foramina distance is $54.16 \pm 9.22 \mathrm{~mm}$. The measurement of the mental foramen laterally from the midline shows a reading of $27.47 \pm 5.10$ and $26.69 \pm 4.97 \mathrm{~mm}$ on the right and left sides respectively.

Our study is comparable to the other studies by Apinhasmit et al, ${ }^{8}$ Agthong et al, ${ }^{6}$ and Yesilyurt et al. ${ }^{14}$ Apinhasmit et $\mathrm{al}_{1}^{8}$ who measured the distance among the Thai population, have recorded an average reading of $28.83 \mathrm{~mm}$ from the symphysis menti. Similarly, with not much of a difference, Agthong et $\mathrm{ll}^{6}$ documented an average reading of $28 \mathrm{~mm}$ among the Thai. Lastly, comparing with the Turkish population steered by Yesilyurt et al, ${ }^{14}$ the measurements of the mental foramen laterally from the midline have shown a substantial difference with the reading of $19.18 \mathrm{~mm}$ on the right side and $19.37 \mathrm{~mm}$ on the left.

The limitation of our study is the usage of two dimensional image of OPG and small sample size. Therefore, it is recommend to utilize the three dimensional (3D) conebeam computed topography (CBCT) with larger sample size to improve the research quality and outcomes. 


\section{CONCLUSION}

The most prevalent intermental foramina distance is Type III $\left(55-60^{+} \mathrm{mm}\right)$ in all the three races of Malaysian populations. There is no relationship between ethnicity and interforamina distance. Clinician must always take into consideration that the intermental foramina distance should not be determined based on their ethnicity.

\section{ACKNOWLEDGMENT}

Authors would like to thank Mr. Mohammed Zaki Noor Al-Hashimi, biostatistics lecturer in MAHSA University, Malaysia, for his great support and effort.

\section{REFERENCES}

1. Al-Juboori MJ, Al-Wakeel HA, Suwen F, Meiyun C. Location of mental foramen among Malaysian population: retrospective study by using orthopantamogram. World J Med Med Sci Res 2013 Oct;1(5):85-90.

2. Singh R, Srivastav AK. Study of position, shape, size and incidence of mental foramen and accessory mental foramen in Indian adult skulls. Int J Morphol 2010;28(4):1141-1146.

3. Shankland WE. The position of the mental foramen in Asian Indians. J Oral Implantol 1994;20(2):118-123.

4. Fishel D, Buchner A, Hershkowith A, Kaffe I. Roentgenologic study of the mental foramen. Oral Surg Oral Med Oral Pathol 1976 May;41(5):682-686.

5. Greenstein G, Tarnow D. The mental foramen and nerve: clinical and anatomical factors related to dental implant placement: a literature review. J Periodontol 2006 Dec;77(12): 1933-1943.

6. Agthong S, Huanmanop T, Chentanez V. Anatomical variations of the supraorbital, infraorbital, and mental foramina related to gender and side. J Oral Maxillofac Surg 2005 Jun;63(6):800-804.

7. Neiva RF, Gapski R, Wang HL. Morphometric analysis of implant-related anatomy in Caucasian skulls. J Periodontol 2004 Aug;75(8):1061-1067.

8. Apinhasmit W, Chompoopong S, Methathrathip D, Sansuk R, Phetphunphiphat W. Supraorbital Notch/Foramen, Infraorbital Foramen and Mental Foramen in Thais: anthropometric measurements and surgical relevance. J Med Assoc Thai 2006 May;89(5):675-682.

9. Kim IS, Kim SG, Kim YK, Kim JD. Position of the mental foramen in a Korean population: a clinical and radiographic study. Implant Dent 2006 Dec;15(4):404-411.

10. Wang TM, Shih C, Liu JC, Kuo KJ. A clinical and anatomical study of the location of the mental foramen in adult Chinese mandibles. Acta Anat (Basel) 1986;126(1):29-33.

11. Udhaya K, Saraladevi KV, Sridhar J. The morphometric analysis of the mental foramen in adult dry human mandibles: a study on the South Indian population. J Clin Diagn Res 2013 Aug;7(8):1547-1551.

12. Gupta S, Soni JS. Study of anatomical variations and incidence of mental foramen and accessory mental foramen in dry human mandibles. Natl J Health Res 2012 Mar;2(1):28-30.

13. Prabodra LBL, Nanayakkara BG. The position, dimension and morphological variations of mental foramen in mandibles. Galle Med J 2006 Sep;11(1):13-15.

14. Yesilyurt H, Aydinlioglu A, Kavakli A. Local differences in the position of the mental foramen. Folia Morphol (Warsz) 2008 Feb;67(1):32-35. 